\title{
Study of Glioblastomas According to Clinicopathological Parameters
}

\author{
Tamás Csaba Sipos¹, Attila Kövecsi², Simona Gurzu², Lóránd Dénes , Annamária Szántó1, \\ Gergő Ráduly', Zsuzsanna Pap \\ 1 Department of Anatomy and Embryology, "George Emil Palade" University of Medicine, Pharmacy, Science and Technology, Târgu \\ Mureș, Romania \\ 2 Department of Pathology, "George Emil Palade" University of Medicine, Pharmacy, Science and Technology, Târgu Mureș, Romania
}

\section{CORRESPONDENCE}

\section{Gergő Ráduly}

Str. Gheorghe Marinescu nr. 38

540139 Târgu Mureș, Romania

Tel: +40 265215551

E-mail: gergo.raduly@umfst.ro

\section{ARTICLE HISTORY}

Received: March 24, 2021

Accepted: December 25, 2021
Tamás Csaba Sipos • Str. Gheorghe Marinescu nr. 38 540139 Târgu Mureș, Romania. Tel: +40 265215 551, E-mail: tamas.sipos@umfstro

Attila Kövecsi • Str. Gheorghe Marinescu nr. 38 540139 Târgu Mureș, Romania. Tel: +40 265215551 E-mail: attila.kovecsi@umfstro

Simona Gurzu • Str. Gheorghe Marinescu nr. 38 540139 Târgu Mureș, Romania. Tel: +40 265215 551, E-mail: simona.gurzu@umfst.ro

Lóránd Dénes • Str. Gheorghe Marinescu nr. 38 540139 Târgu Mureș, Romania. Tel: +40 265215 551, E-mail: denes.lorand@gmail.com

Annamária Szántó • Str. Gheorghe Marinescu nr. 38 540139 Târgu Mureș, Romania. Tel: +40 265215 551, E-mail: annamaria.szanto@umfst.ro

Zsuzsanna Pap • Str. Gheorghe Marinescu nr. 38 540139 Târgu Mureș, Romania. Tel: +40 265215 551, E-mail: zsuzsanna.pap@umfst.ro

\begin{abstract}
Background: Glioblastomas are the most common tumors of the central nervous system. The incidence of brain tumors is higher in developed countries and is constantly increasing. Aim of the study: The purpose of this study was to analyze the clinicopathological data of patients diagnosed with glioblastomas from a selected case series. Material and methods: This retrospective, single-center study was conducted on glioblastoma cases diagnosed between 2014 and 2018 at the Department of Pathology of the County Emergency Clinical Hospital of Târgu Mureș, Romania. The information was centralized from histopathology reports and focused on the location of glioblastomas and demographic parameters (gender and age of patients). Results: In the studied period, there were 154 patients diagnosed with glioblastoma, of which 50.65\% were men. The most affected age group was $61-70$ years (31.17\% of cases). In most cases (49.35\%), the glioblastoma was located in the left cerebral hemisphere, and the most affected lobes were the frontal (29.87\%), temporal (26.62\%), and parietal (14.94\%). We could not find a statistically significant association between the distribution of cases by years, gender, and location of the tumor. Conclusions: Glioblastoma is a tumor that involves the left cerebral hemisphere most often and affects both genders over the age of sixty.
\end{abstract}

Keywords: glioblastoma, age, gender, localization

\section{INTRODUCTION}

Gliomas are the most aggressive tumors of the central nervous system. According to the classification of the WHO, diffuse gliomas are subdivided into astrocytomas, oligodendrogliomas, and glioblastomas. ${ }^{1,2}$ Among diffuse gliomas, glioblastoma is the most malignant type (grade IV), displaying a diffuse growth and resistance to chemotherapeutic agents. Most cases are primary malignant and do not display mutations for the isocitrate dehydrogenase 1 gene (IDH-wildtype glioblastomas). Secondary glioblastomas are IDH-mutant cases and occur as a result of dedifferentiation from diffuse grade II or III gliomas. ${ }^{1}$ Tumor cell proliferation is also influenced by genetic and environmental factors. 
The incidence of brain tumors is higher in developed countries, with differences between ethnic and racial groups. The annual incidence is between $0.59-5 / 100,000$ people, with high numbers of cases reported in South America, South and Eastern Europe, and low numbers reported in East Asia. In terms of age, the most affected age groups are over 55 years, and the male to female ratio ranges from $1: 1$ to $2.7: 1$. Overall, the median survival of glioblastoma patients is between 16 and 22 months, in favor of female patients. ${ }^{1,3-5}$

Glioblastomas are located especially in the supratentorial region of the central nervous system. Primary glioblastomas occur more frequently in the temporal, parietal, and frontal lobes. Considering the accelerated expansion of the tumor, it usually invades several lobes with a tendency to proliferate towards the deep areas and to the contralateral hemisphere. Secondary glioblastomas are located mainly in the frontal lobe, frequently in the right cerebral hemisphere, uncommon in central cerebral areas. ${ }^{6}$

The therapeutic management consists in surgical resection, followed by chemotherapy with temozolomidebased or other agents in combination with radiotherapy. ${ }^{7-9}$ There is currently no second line of treatment, although bevacizumab, an anti-VEGF chemotherapeutic, has been used alone or in combination but has not yet been approved in Europe for the treatment of glioblastomas. ${ }^{10}$
Despite improving therapy, the incidence of glioblastomas is increasing constantly, and it remains an important cause of cancer death in adults.

The aim of this study was to perform an initial assessment of the clinicopathological parameters of consecutive cases of glioblastomas, as a starting point for further studies.

\section{MATERIAL AND METHODS}

This retrospective, single-center study was conducted at the Department of Pathology of the County Emergency Clinical Hospital of Târgu Mureș, Romania. The study included all consecutive patients diagnosed with glioblastoma between 2014 and 2018 who underwent surgery.

For a preliminary database, demographic and tumor parameters were centralized from the histopathology reports. Analyzed tumor parameters included localization (frontal lobe, temporal lobe, parietal lobe) and orientation for the cerebral hemisphere (left, right, or central localization). Statistical analysis of the data was carried out using GraphPad InStat 3, version 3.06 (GraphPad Software Inc, San Diego, USA). The statistical significance was set for a value of $p<0.05$ ( $95 \%$ confidence interval). This research was approved by the Ethics Committee of the Emergency Clinical County Hospital of Târgu Mureș, Romania.

TABLE 1. Demographic, clinical and metabolic characteristics of patients with T2DM without and with DRD

\begin{tabular}{|c|c|c|c|c|c|c|c|c|c|c|}
\hline & \multicolumn{2}{|c|}{2014} & \multicolumn{2}{|c|}{2015} & \multicolumn{2}{|c|}{2016} & \multicolumn{2}{|c|}{2017} & \multicolumn{2}{|c|}{2018} \\
\hline & M & $\mathbf{F}$ & M & $\mathbf{F}$ & $\mathbf{M}$ & $\mathbf{F}$ & M & $\mathbf{F}$ & $\mathbf{M}$ & $\mathbf{F}$ \\
\hline \multicolumn{11}{|l|}{ Age (years) } \\
\hline $1-10$ & 0 & 0 & 0 & 0 & 0 & 1 & 0 & 1 & 0 & 0 \\
\hline $21-30$ & 0 & 0 & 0 & 0 & 1 & 0 & 1 & 1 & 0 & 0 \\
\hline $31-40$ & 1 & 2 & 2 & 0 & 1 & 3 & 2 & 1 & 0 & 1 \\
\hline $41-50$ & 5 & 0 & 1 & 0 & 5 & 2 & 3 & 1 & 2 & 5 \\
\hline $51-60$ & 9 & 3 & 2 & 5 & 3 & 9 & 2 & 3 & 4 & 4 \\
\hline $61-70$ & 6 & 4 & 3 & 4 & 3 & 4 & 7 & 6 & 3 & 8 \\
\hline $71-80$ & 3 & 1 & 1 & 1 & 4 & 2 & 2 & 2 & 2 & 1 \\
\hline$>80$ & 0 & 0 & 0 & 0 & 0 & 1 & 0 & 0 & 0 & 0 \\
\hline \multicolumn{11}{|l|}{ Orientation } \\
\hline Left hemisphere & 10 & 4 & 5 & 5 & 9 & 6 & 11 & 8 & 6 & 12 \\
\hline Right hemisphere & 12 & 4 & 4 & 5 & 8 & 14 & 6 & 7 & 4 & 5 \\
\hline Central area & 0 & 0 & 0 & 0 & 0 & 2 & 0 & 0 & 1 & 0 \\
\hline Left hemisphere/right hemisphere & 0.83 & 1 & 1.25 & 1 & 1.12 & 0.42 & 1.83 & 0.87 & 1.5 & 2 \\
\hline \multicolumn{11}{|l|}{ Localization } \\
\hline Frontal lobe & 5 & 5 & 2 & 3 & 4 & 7 & 6 & 2 & 3 & 9 \\
\hline Temporal lobe & 4 & 1 & 2 & 2 & 7 & 7 & 6 & 8 & 1 & 3 \\
\hline Parietal lobe & 5 & 1 & 3 & 3 & 2 & 2 & 2 & 1 & 2 & 2 \\
\hline
\end{tabular}




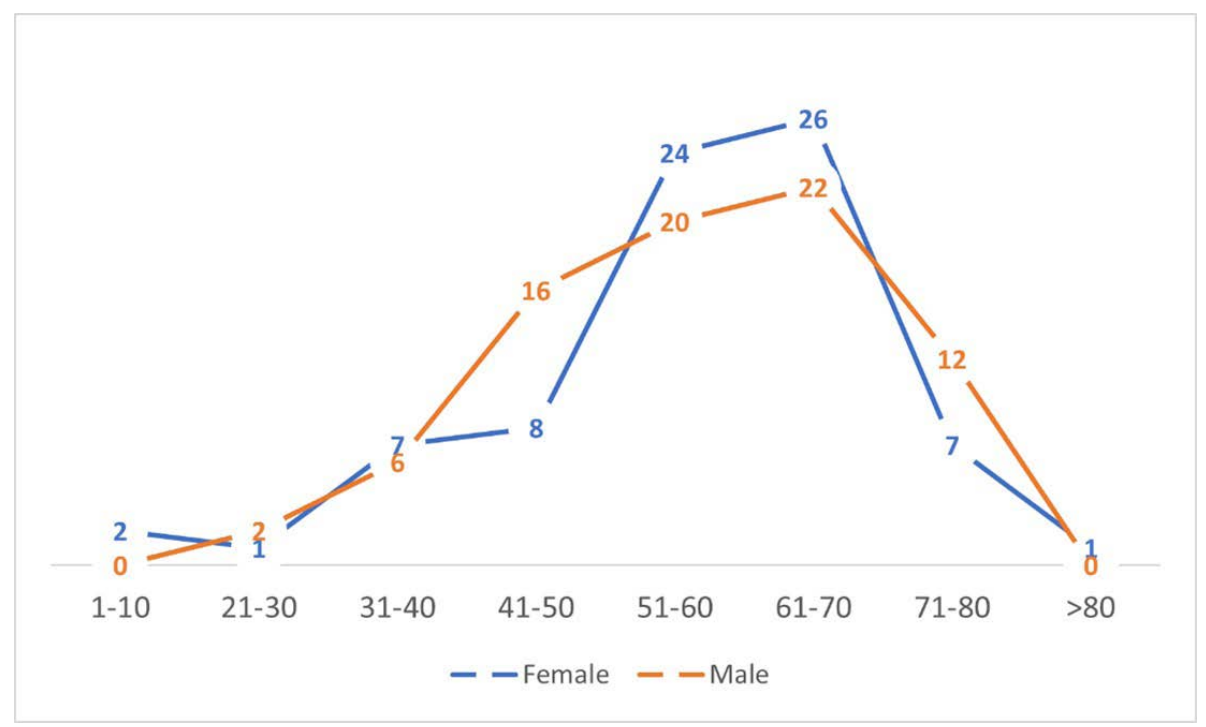

FIGURE 1. Incidence of glioblastomas according to age groups and gender

\section{RESULTS}

Between 2014 and 2018, a total of 154 patients have been diagnosed with glioblastoma at the Department of Pathology of the County Emergency Clinical Hospital of Târgu Mures, Romania. The mean age was 57 years (range 8-81 years). A relatively equal distribution was seen between genders, $50.65 \%$ of cases $(78 / 154)$ being male and $49.35 \%$ (76/154) female. The male to female ratio was 1.02:1.

Regarding age distribution, glioblastomas were more frequent in patients aged $61-70$ years $(31.17 \%, 48 / 154)$, followed by patients aged $51-60$ years $(28.57 \%, 44 / 154)$. An extremely low number of cases were found in patients aged $1-20$ years and $>80$ years $(1.95 \%, 3 / 154)$ (Table 1$)$.
The male to female ratio was $1: 1.18$ in the $51-60$ years and $1: 1.2$ in the $61-70$ years age group, with more females than males, while in the $41-50$ years and $71-80$ years age groups it was 1.7:1 and 2:1, respectively, with more males than females. We could not demonstrate a statistically significant association between age and gender $(\mathrm{p}=0.32)$ (Figure 1$)$.

Regarding the orientation of glioblastomas, most of the tumors involve a single hemisphere. In most of the analyzed cases $(49.35 \%, 76 / 154)$ the tumor was located in the left cerebral hemisphere, and in $44.81 \%(69 / 154)$ in the right cerebral hemisphere (Table 1).

Regarding the anatomical location within the cerebral hemisphere, most of the cases were located in the frontal

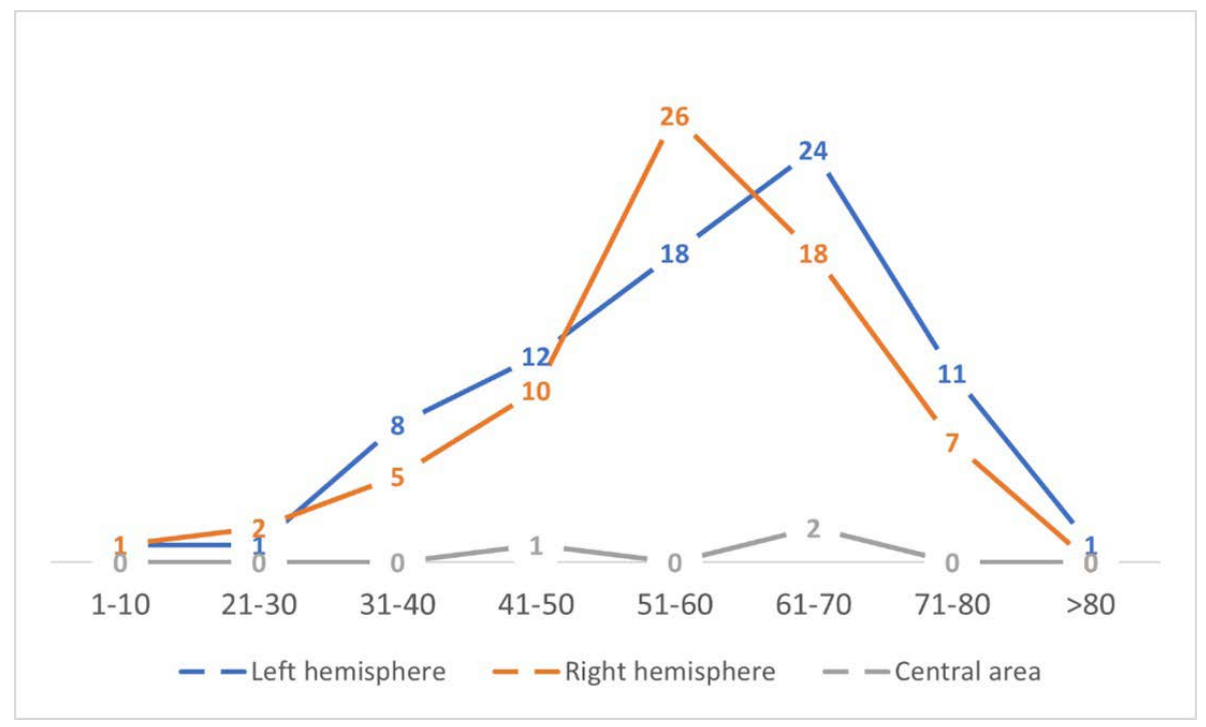

FIGURE 2. Incidence of glioblastomas according to age group and tumor orientation 


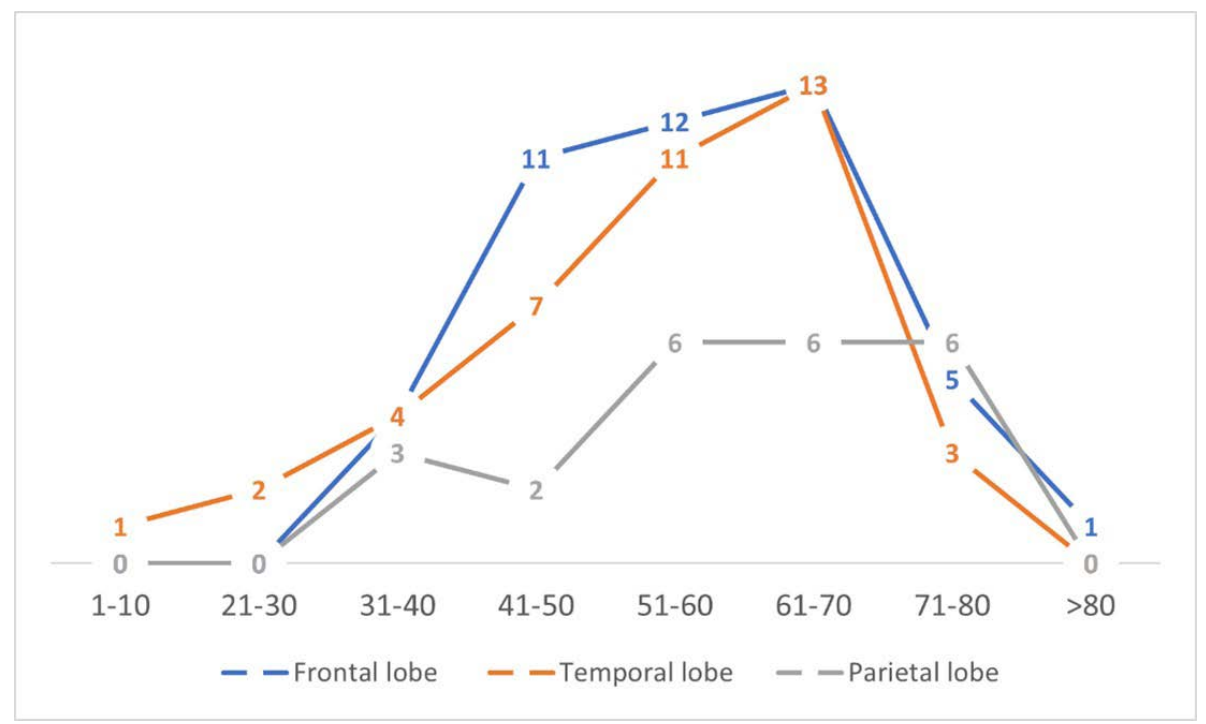

FIGURE 3. Incidence of glioblastomas according to age group and tumor location

(29.87\%, 46/154), temporal $(26.62 \%, 41 / 154)$, and parietal $(14.94 \%, 23 / 154)$ lobes. Corpus callosum, thalamus, or intraventricular localization were uncommon, with 2-3 cases each. Glioblastomas located in the temporal and frontal lobes were more frequent in females, while those located in the parietal lobe were more frequent in males, but the difference was not significant $(\mathrm{p}=0.16)$ (Table 1).

Considering the orientation and localization of glioblastomas, the ratio between left hemisphere/right hemisphere orientation was 1.875 in the frontal lobe, 0.952 in the temporal lobe, and 0.916 in the parietal lobe. As far as the relation between tumor localization and the patients' gender is concerned, the male to female ratio over the entire analyzed period was 1:1.3 in case of tumors located in the frontal lobe, 1:1.05 for tumors located in the temporal lobe, and 1.55:1 for tumors located in the parietal lobe.

We did find a statistically significant association between tumor localization and orientation $(p=0.32)$. Most of the age groups showed left predominance, except patients between 51 and 60 years, where the tumors were more frequent in the right hemisphere $(\mathrm{p}=0.83)$ (Figure 2 ). In the majority of the age groups, the most affected region was the frontal lobe, followed by the temporal and parietal lobes $(p=0.51)$ (Figure 3$)$.

The highest number of glioblastomas were diagnosed in $2016(25.32 \%, 39 / 154)$ and 2014 (22.08\%, 34/154). In contrast, very few cases were diagnosed in 2015 (12.34\%, 19/154). Most of the patients diagnosed in 2014 (30.76\%, $24 / 78$ ) were males, with a male to female ratio of $2.4: 1$.

TABLE 2. Distribution of glioblastomas by gender - results from the current analysis and comparison of data with similar studies

\begin{tabular}{llllll}
\hline & Years & $\begin{array}{l}\text { Total no. } \\
\text { of cases }\end{array}$ & Male & Female & $\begin{array}{l}\text { Male to } \\
\text { female } \\
\text { ratio }\end{array}$ \\
\hline Present study & $2014-2018$ & 154 & 78 & 76 & 1.02 \\
Grech et al.5 & $2008-2017$ & 100 & 61 & 39 & 1.56 \\
Shah et al. ${ }^{9}$ & $1999-2010$ & 6,039 & 3,153 & 2,886 & 1.09 \\
Eriksson et al.10 & $1995-2015$ & 571 & 352 & 219 & 1.60 \\
Yang et al.11 & Unavailable & 371 & 227 & 144 & 1.57 \\
Tian et al.12 & $2000-2008$ & 6586 & 4,049 & 2,537 & 1.59 \\
Hansen et al.13 & $2009-2014$ & 1,364 & 828 & 536 & 1.54 \\
Behzadnia et al.14 & $1999-2015$ & 58 & 35 & 23 & 1.52 \\
Korja et al.15 & $2000-2013$ & 2,045 & 1,191 & 854 & 1.39 \\
Nizamutdinov et al. ${ }^{16}$ & $1976-2013$ & 645 & 345 & 300 & 1.15 \\
Liang et al.17 & $2015-2018$ & 335 & 190 & 145 & 1.31 \\
\hline
\end{tabular}


TABLE 2. Distribution of glioblastomas by gender - results from the current analysis and comparison of data with similar studies

\begin{tabular}{llllll}
\hline & Years & $\begin{array}{l}\text { Total no. } \\
\text { of cases }\end{array}$ & $\begin{array}{l}\text { Frontal } \\
\text { lobe }\end{array}$ & $\begin{array}{l}\text { Temporal } \\
\text { lobe }\end{array}$ & $\begin{array}{l}\text { Parietal } \\
\text { lobe }\end{array}$ \\
\hline Present study & $2014-2018$ & 154 & 46 & 41 & 23 \\
Grech et al. & $2008-2017$ & 100 & 25 & 21 & 23 \\
Tian et al. ${ }^{2}$ & $2000-2008$ & 6,586 & 1,663 & 1,556 & 1,097 \\
Hansen et al.13 & $2009-2014$ & 1364 & 415 & 437 & 258 \\
Behzadnia et al.14 & $1999-2015$ & 58 & 10 & 6 & 9 \\
Nizamutdinov et al.16 & $1976-2013$ & 645 & 184 & 134 & 136 \\
\hline
\end{tabular}

In 2015 , both males and females were diagnosed relatively equally (male to female ratio of $0.9: 1$ ). Most female cases were diagnosed in $2016(28.95 \%, 22 / 76)$, while the least number of cases were recorded in 2014 and 2015 (26.32\%, 20/76).

The analysis did not reveal a statistically significant association between case distribution over the years and the gender of patients $(\mathrm{p}=0.06)$, tumor orientation $(\mathrm{p}=0.33)$, and localization $(\mathrm{p}=0.08)$. The most frequently involved hemisphere was the left one; the left hemisphere/right hemisphere ratio ranged between 0.68 and 2 ( 0.68 in 2016, 0.87 in 2014, 1.11 in 2015, 1.46 in 2017, and 2 in 2018). Most of the cases with central localization were diagnosed in $2016(2 / 3)$.

\section{DISCUSSIONS}

Current data show that glioblastomas develop more frequently in the right cerebral hemisphere. In contrast with these data, we found a predominance of tumor location in the left cerebral hemisphere. ${ }^{6}$ We also found infrequent central or intraventricular tumors.

Current epidemiological data show differences between males and females regarding the incidence of glioblastomas, with a male to female ratio ranging between 1.09:1 and 1.6:1 (Table 2).5,9-17 In contrast with these data, we found a relatively equal distribution between genders.

Similarly to other reports (Table 3), 5,12-14,16 we found glioblastomas in the frontal, temporal, and parietal lobes. In a cohort of patients from Denmark, Hansen $e t$ al. found glioblastomas located predominantly in the temporal lobe. ${ }^{13}$

In Europe, the estimated mean age at the time of diagnosis of astrocyte-derived tumors is 53 years, which is similar to the age distribution found in our analysis.

\section{CONCLUSIONS}

Glioblastomas are tumors that affect both genders and develop more frequently in the left cerebral hemisphere and in the frontal lobe. In our geographical area, they appear predominantly in patients aged between 50 and 80 years.

\section{CONFLICT OF INTEREST}

Nothing to declare.

\section{REFERENCES}

1. Louis DN, Perry A, Reifenberger G, et al. The 2016 World Health Organization Classification of Tumors of the Central Nervous System: a summary. Acta Neuropathol. 2016;131:803-820.

2. Ostrom QT, Gittleman H, Xu J, et al. CBTRUS Statistical Report: Primary Brain and Other Central Nervous System Tumors Diagnosed in the United States in 2009-2013. Neuro Oncol. 2016;18(suppl_5):v1-v75.

3. Miranda-Filho A, Piñeros M, Soerjomataram I, Deltour I, Bray F. Cancers of the brain and CNS: global patterns and trends in incidence. Neuro Oncol. 2017:19:270-280.

4. Ostrom QT, Rubin JB, Lathia JD, et al. Females have the survival advantage in glioblastoma. Neuro Oncol. 2018;20:576-577.

5. Grech N, Dalli T, Mizzi S, et al. Rising Incidence of Glioblastoma Multiforme in a Well-Defined Population. Cureus. 2020;12:e8195.

6. Tang $Q$, Lian $Y, Y u ~ J$, et al. Anatomic mapping of molecular subtypes in diffuse glioma. BMC Neurology. 2017;17:183.

7. Yersal O. Clinical outcome of patients with glioblastoma multiforme: Single center experience. Journal of Oncological Sciences. 2017;3:123-126.

8. Li R, Chen X, You Y, et al. Comprehensive portrait of recurrent glioblastoma multiforme in molecular and clinical characteristics. Oncotarget. 2015;6:30968-30974

9. Shah BK, Bista A, Sharma S. Survival Trends in Elderly Patients with Glioblastoma in the United States: a Population-based Study. Anticancer Res. 2016;36:4883-4886.

10. Eriksson M, Kahari J, Vestman A, et al. Improved treatment of glioblastoma - changes in survival over two decades at a single regional Centre. Acta Oncol. 2019;58:334-341.

11. Yang W, Warrington NM, Taylor SJ, et al. Sex differences in GBM revealed by analysis of patient imaging, transcriptome, and survival data. Sci Trans/ Med. 2019;11:eaao5253.

12. Tian M, Ma W, Chen $Y$, et al. Impact of gender on the survival of patients with glioblastoma. Biosci Rep. 2018;38:BSR20180752.

13. Hansen S, Rasmussen BK, Laursen RJ, et al. Treatment and survival of glioblastoma patients in Denmark: The Danish Neuro-Oncology Registry, 2009-2014. J Neurooncol. 2018;139:479-489.

14. Behzadnia $H$, Alijani B, Emamhadi M, et al. Glioblastoma Multiforme: A Single Hospital Experience. Iran J Neurosurg. 2015;1:16-20.

15. Korja M, Raj R, Seppä K, et al. Glioblastoma survival is improving despite increasing incidence rates: a nationwide study between 2000 and 2013 in Finland. Neuro Oncol. 2019;21:370-379.

16. Nizamutdinov D, Stock EM, Dandashi JA, et al. Prognostication of Surviva Outcomes in Patients Diagnosed with Glioblastoma. World Neurosurg. 2018;109:e67-e74.

17. Liang J, Lv X, Lu C, et al. Prognostic factors of patients with Gliomas - an analysis on 335 patients with Glioblastoma and other forms of Gliomas. BMC Cancer. 2020;20:35. 